\title{
İnatçı kusma ve malnütrisyonun ayırıcı tanısında duodenal web
}

\section{Duodenal web in the differential diagnosis of persistent vomiting and malnutrition}

\section{Neslihan KARACABEY ${ }^{1}$, Eylem SEVINÇ ${ }^{1}$, Serkan TÜRKUÇAR ${ }^{2}, Z_{\text {ehra VATANSEVER }}^{2}$, Duran ARSLAN ${ }^{1}$}

Erciyes Üniversitesi Tıp Fakültesi ${ }^{1}$ Çocuk Gastroenterolojisi Bilim Dalı, ${ }^{2}$ Çocuk Sağhığı ve Hastalıkları Anabilim Dalı, Kayseri

Duodenal atrezi ve darlık konjenital barsak tıkanıklığının sık görülen nedenlerindendir. Duodenal web (perde) ön barsağın anormal embriyolojik gelişimi nedeniyle oluşan nadir görülen konjenital duodenal darlık nedenlerinden birisidir. Çocuklarda inatçı kusma, karın şişkinliği ve büyüme geriliğine sık rastlanmaktadır. Tanıda baryumlu pasaj grafileri ve endoskopik inceleme yardımcı olabilir. Bu yazıda inatçı kusmaları ve büyüme geriliği olan, yanlışlıkla gastroözefageal reflü tanısı alan duodenal web tespit edilen bir olguyu sunduk.

Anahtar Kelimeler: Malnütrisyon, perde, kusma
Duodenal atresia and stenosis are a common cause of congenital bowel obstruction. Duodenal web is rare, and is a type of congenital duodenal obstruction that occurs by abnormal embryological foregut development. Children with duodenal web are frequently presented with persistent vomiting, abdominal distention and growth retardation. Barium passage graphy and endoscopy are helpful in the diagnosis. In this article, we report an infant with duodenal web who had been investigated because of persistent vomiting and growth retardation, and who was misdiagnosed as gastroesophageal reflux.

Keywords: Malnutrition, web, vomiting

doğduktan kısa bir süre sonra başladığı ve reflü tanısıyla çeşitli ilaçlar kullandığı öğrenildi. Fizik muayenesinde cilt altı yă̆ dokusunun azlığı dışında patolojik bulgu saptanmayan hastanın boyu $70 \mathrm{~cm}$ (25-50 p) ve vücut ağırlığı 6700 gram (<3 p) idi. Yaşa göre ağırlık \%66 (ağır protein enerji malnütrisyonu) olarak tespit edilen hastanın laboratuvar bakısında

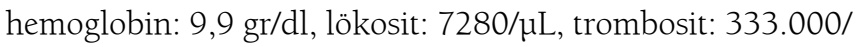
$\mu \mathrm{L}$, total protein: 5,5 gr/dl, albumin: 3,3 gr/dl, kan şekeri: 95 mg/dl, Na: $135 \mathrm{meq} / \mathrm{L}, \mathrm{K}: 4,5 \mathrm{meq} / \mathrm{L}, \mathrm{AST}: 40 \mathrm{U} / \mathrm{L}, \mathrm{ALT}: 9$ $\mathrm{U} / \mathrm{L}$, idrar ve gayta bakıları (gayta yağ, PH, redüktan madde) normaldi. Abdominal ultrasonografisinde patolojik bulgu saptanmadi. Baryumlu özofagus, mide, duodenum grafisinde bulbus dilate olarak izlendi ve dış bası, web olabileceği şeklinde raporlandı (Resim 1).

Üst gastrointestinal sistem endoskopisinde bulbusun çok dilate olduğu görüldü, bulbus çıkışında web izlendi, duodenum 2. kısıma geçilemedi (Resim 2).

Hastaya çocuk cerrahisi tarafindan gastrojejunostomi operasyonu yapilarak web eksize edildi. Hastanın takibinde kusma yakınması olmadı ve kilo alımı görüldü.

\section{TARTIŞMA}

Duodenal atrezi ilk olarak 1733'de Calder tarafindan intestinal obstrüksiyon nedeni olarak tanımlanmıştır. 1931'de 


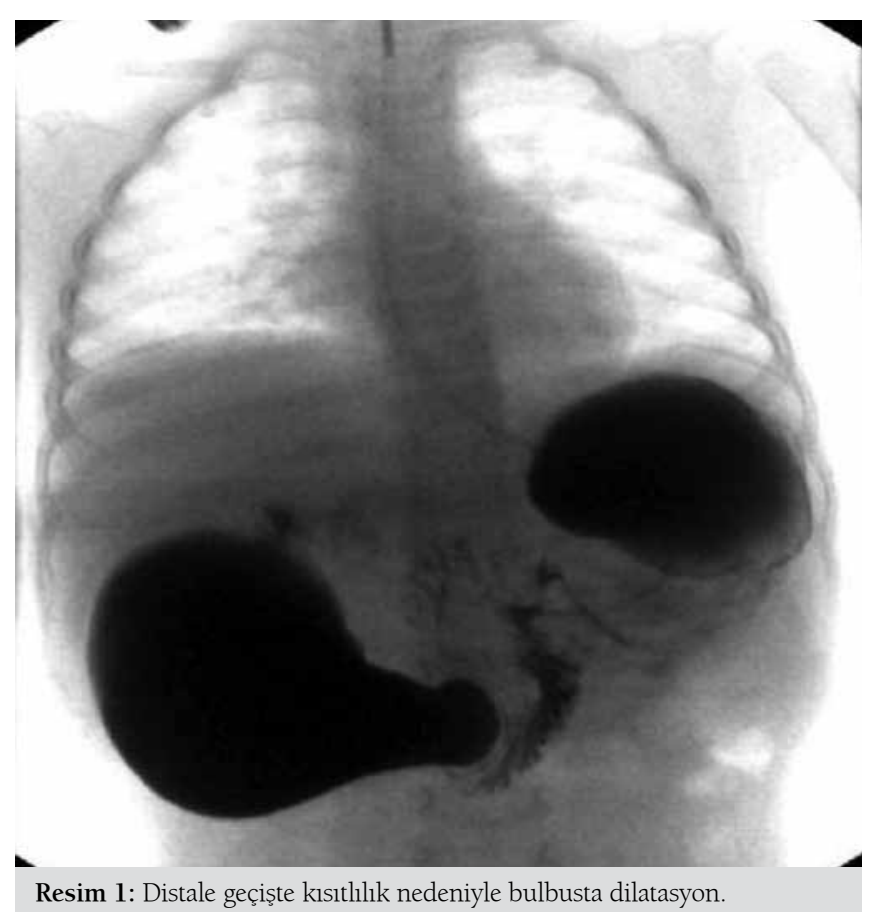

250 duodenal atrezili vakadan sadece 9 yaşayan olgu sunulmuştur. Önceleri \%86-90 olan mortalite oranları cerrahi yöntemlerle günümüzde \%4'e gerilemiştir. Duodenal atrezi, embriyolojik dönemde foreguttan gelişen distal duodenum ile midguttan gelişen proksimal kısmın birleşme ve rekanalizasyonu sırasında ortaya çıan sorunlar nedeniyle oluşur. Tip 1 duodenal atrezi en sik görülen tiptir ve genellikle lümeni oklüze eden bir membran "web" vardır (Tip la), bazen bu membranda fenestrasyonlar olabilir (Tip 1b), yaygin bir formu olan 'wind-sock' anomalisi proksimal membranın distal segment içine birkaç santimetre girmesi ile oluşur (Tip lc). Tip 2 duodenal atrezide proksimal ve distal segment arasında fibroz bir bant varken Tip 3'de ise iki kör segment vardır (5-7).

Konjenital duodenal obstrüksiyon yenidoğan döneminde yaygındır, tüm intestinal atrezilerin \%49'nu oluşturur. Duodenal atrezi ve stenozun kombine insidansı 1/7000'dir. Duodenal obstruksiyonlarda üst seviyede tıkanıklık olduğu için genellikle infant döneminde bulgu verir. Web, pre ya da postpapiller duodenumda lokalize olabilir, sırası ile safrasız veya safralı kusmaya yol açabilir. Infantil dönemde en yaygın klinik bulgular bulantı ve inatçı kusmalardır $(8,9)$. Bu olgularda distalde tıkanıklık nedeni ile besinler ileriye geçemez ve midede dolgunluk nedeni ile tokluk hissi, iştahsızlık ve kusma gözlenir. Bizim olgumuzda bulbusta Tip la duodenal darlık söz konusuydu, bu nedenle kusması safrasızdı, sık kusma ve beslenme yetersizliği nedeni ile büyüme geriliği gelişmişti.

Duodenal atrezinin en çok Down sendromu olmak üzere, VACTREL (vertebral, anorektal, kardiyak, trakeoözofageal,

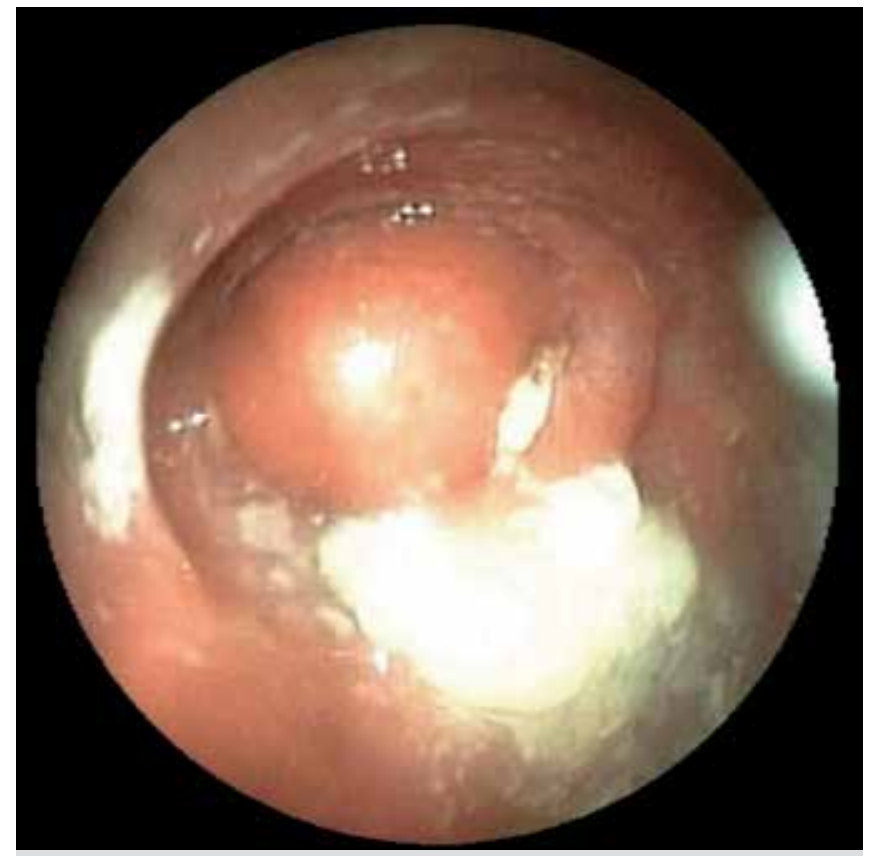

Resim 2. Bulbusta lümeni kapatan web.

renal ve ekstremite anomalileri) sendromuyla da birlikteliği tanımlanmıştır $(2,7)$. Hastamızın sendromik görünümü yoktu ve eşlik edebilecek anomaliler açısından yapılan abdominal ultrasonografisi de normaldi.

Tanıda kontrastlı üst gastrointestinal sistem pasaj grafisi ve üst gastrointestinal sistem endoskopisi yardımcı olabilir. Hastaların ayakta direkt batın grafilerinde proksimal duodenumun hava ile dilatasyonu veya 'double-bubble sign' bulgusu saptanabilir $(7,10)$. Kontrastlı özofagus mide duodenum tetkikinde ise bizim olgumuzda da olduğu gibi kontrast maddenin distale geçişinde gecikme olduğu görülür. Web’i olan hastaların endoskopik bakılarında bulbusta genişleme, duodenum ikinci kısmına geçilememesi gibi nonspesifik bulgulara rastlanabilir. Olgumuzun endoskopisinde bulbusun ileri derecede geniş olduğu, duodenumun ikinci kısmına geçişe izin vermeyen duodenal web saptandl.

Hastalığın nihai tedavisi webin duodenojejunostomi, gastrojejunostomi gibi yöntemlerle çıkarılmasıdır (10). Ayrıca bu olgularda laparoskopik cerrahi ve endoskopik yöntemlerle tedavi de mümkündür $(11,12)$. Bizim olgumuzda uygulanan gastrojejunostomi işlemi sonrasında hastamızın şikayetleri geriledi.

Sonuç olarak inatçı kusma ve büyüme geriliği olan infantların ayırıcı tanısında konjenital anomalilerin her zaman akılda tutulması gerekmektedir, bu sayede kesin tedavisi mümkün olan hastalıkta gereksiz medikal tedavilerle zaman kaybedilmeden büyüme geriliği gibi istenmeyen sonuçların önüne geçilebilir. 


\section{KAYNAKLAR}

1. Kshirsagar AY, Sulhyan SR, Vasisth G, Nikam YP. Duodenal stenosis in a child. Afr J Paediatr Surg 2011;8:92-4.

2. Escobar MA, Ladd AP, Grosfeld JL, et al. Duodenal atresia and stenosis: long-term follow-up over 30 years. J Pediatr Surg 2004;39:867-71.

3. Tzeng GY, Lin CC, Chen HC, et al. Congenital duodenal web in late infancy and childhood: a report of two cases. Zhonghua Yi Xue Za Zhi (Taipei) 1994:53:307-10.

4. Saha N, Hasanuzaman SM, Chowdhury LH, Talukder SA. Congenital duodenal web (wind-soak variety) in the fourth part of the duodenum causing obstruction in a female child. Mymensingh Med J 2012;21:745-8

5. Yılmaz A, Akçam M, Duman Ö, et al. Inatçı kusma ve ishal nedeniyle epilepsi yanlıs tanısı alan rüzgar çorabı tipi duodenal perde: Bir vaka takdimi. Çocuk Sağlığı ve Hastalıkları Dergisi 2007;50:111-3.

6. Melek M, Edirne YE. Two cases of duodenal obstruction due to a congenital web. World J Gastroenterol 2008;14:1305-7.
7. Arca MJ, Oldham KT. Small and Large Bowel Stenosis and Atresias. In: Wyllie R, Hyams J and Kay M (eds). Pediatric Gastrointestinal and Liver Disease 4th ed. Philadelphia: Saunders Elsevier 2011;598-600.

8. Hill S, Koontz CS, Langness SM, Wulkan ML. Laparoscopic versus open repair of congenital duodenal obstruction in infants. J Laparoendosc Adv Surg Tech A 2011;21:961-3.

9. Muensterer OJ, Hansen EN. Resection of a duodenal web using singleincision pediatric endosurgery. J Pediatr Surg 2011;46:989-93.

10. Yoon $\mathrm{CH}$, Goo HW, Kim EA, et al. Sonographic windsock sign of a duodenal web. Pediatr Radiol 2001; 31: 856-857.

11. Van der Zee DC. Laparoscopic repair of duodenal atresia: revisited. World J Surg 2011;35:1781-4.

12. Lee SS, Hwang ST, Jang NG, et al. A case of congenital duodenal web causing duodenal stenosis in a down syndrome child: endoscopic resection with an insulated-tip knife. Gut Liver 2011;5:105-9. 